RESEARCH PAPER

\title{
AUSTENITIC STAINLESS STEELS MANUFACTURING BY LASER POWDER BED FUSION TECHNIQUE
}

\author{
Andrea Di Schino ${ }^{1)^{*}}$, Paolo Fogarait ${ }^{2}$, Domenico Corapi ${ }^{2}$, Orlando Di Pietro $^{1}$, Chiara Zitelli ${ }^{1}$ \\ ${ }^{1)}$ Università degli Studi di Perugia, Dipartimento di Ingegneria, Perugia, Italy \\ 2) Seamthesis Srl, Piacenza, Italy \\ *Corresponding author: andrea.dischino@unipg.it, Università degli Studi di Perugia, Dipartimento di Ingegneria, Via G. Duranti 93, 06125 Perugia, Italy
}

Received: 10.11 .2019

Accepted: 03.02.2020

\begin{abstract}
In this paper we report about the possibility to process stainless steels by laser powder bed fusion (L-PBF) systems. Austenitic stainless steels are analysed showing the possibility to successfully process them, targeting different applications. In particular, it is shown that stainless steels can be successfully processed and their mechanical behaviour allow them to be put in service. Porosities inside manufactured components are extremely low and comparable to conventionally processed materials. Mechanical performances are even higher than standard requirements. Micro surface roughness typical of the as-built material can act as crack initiator, reducing the strength in both quasi-static and dynamic conditions.
\end{abstract}

Keywords: Stainless steels; laser powder bed fusion; additive manufacturing

\section{INTRODUCTION}

Stainless steels are nowadays applied in quite different applications due to their peculiar properties in terms of strength/ductility requirements coupled with corrosion resistance high targets. In particular, they are adopted in automotive [110], construction and building [11-12], energy [13-15], aeronautical [17], medical [18], food [19-24] and 3D printing [25-29] applications. Additive manufacturing (AM) is an emerging technology able to manufacture near-net-shape components characterized by complex geometries. AM is particularly suited for small production amounts, in particular in those cases requiring part-customization and functional integration: this is why it first emerged as a rapid prototyping technology. The adoption of AM technologies resulted in new production paradigm [30-33] since the designer is now able to project a component, or customize the geometry of an already-existing one, taking into account the final service conditions. At the meantime, AM allows to simplify components assembly by merging different parts in one single monolith.

The possibility to manufacture stainless steel components in laser powder bed fusion (L-PBF) systems, accomplished with a deeper methodology understanding, will result in a larger adoption of the technology itself. Nowadays L-PBF has been already applied to manufacture stainless steel components, but a basic lack in standardisation and correct metrology definition is limiting the possibility to adopt such technology for standard production: for this reason international committees are joining together to accelerate the process. The challenge is to consistently define the ideal processing routes and requirements, standard mechanical requirements, suitable heat treatments, dynamic performances, post-processing and qualification needs. This paper will focus on the state of the art of stainless steel alloys application in L-PBF systems: starting from the working conditions a list of stainless steel grades already tested on L$\mathrm{PBF}$ systems is reported with their main properties.

\section{Austenitic stainless steel processing in L-PBF system}

Stainless steels are worldwide adopted following their peculiar properties combination (both at room and high temperature) thanks to their chemical composition and microstructural details. In L-PBF, the correct steel chemical composition is guaranteed by a wise manipulation and correct storing of adopted metal powders, mainly to avoid the oxygen presence; on the contrary, microstructural features (e.g. grain size, precipitation state) are achieved by 3D printing parameters. In particular, final product microstructure depends on the local heat flow direction, grains competitive growth and laser scanning strategy. Typical cooling rates are in the range 105-106 K/s [34] following the gas atmosphere heat exchange with the not yet fused powder and the underneath material already consolidated: the so obtained solidified microstructure is fine and far from that provided by thermodynamic equilibrium. Moreover, laser scanning strategy impacts on the material texture: for example, in the case of no rotation between subsequent layers during scanning, the as-built material will be characterized by a strong $<001>$ texture as a preferential grain growth direction this will lead to a strongly orthotropic steel behaviour. On the other side, if powder bed is scanned in small islands, also non-consecutive, and rotation of laser between different layers is adopted, an almost untextured microstructure is achieved. Elongated grain structure, along z-direction (according to Figure 1), is due to both heat extraction from the bottom side of the melt pool (i.e. building substrate) and epitaxial grain growth, like fusion welding. In L-PBF the existing base-metal grains (i.e. the grains existing in the last melted layer) act as substrate for nucleation. Moreover, if subsequent layers are melted, this will cause reheating of the already consolidated material, determining solid state phase transformations.

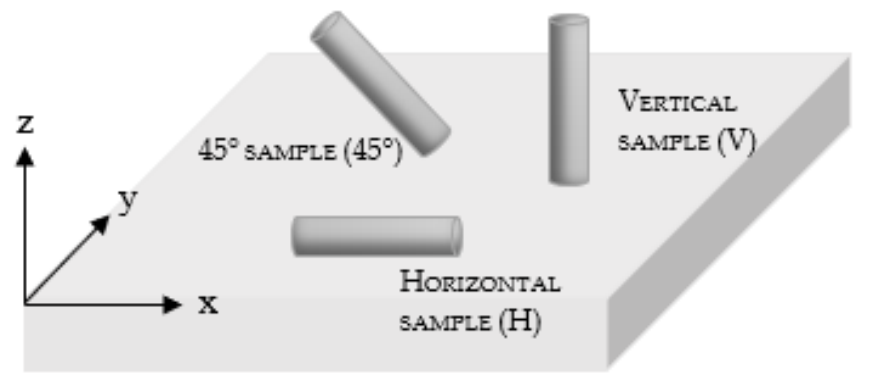

Fig.1 Schematics of commonly projected building directions for tensile specimens.

The particular microstructures coming from the above reported physical phenomena determine different mechanical behaviour as a function of the tested direction or on the service loading condition. This is the reason why the best rule is to produce tensile specimens with their main axis oriented along different directions, as schematised in Figure 1: vertical specimens (V) are representative of commonly identified longitudinal direction, while horizontal specimens $(\mathrm{H})$ of transversal direction. The above reported peculiar metallurgical behaviour of materials produced via AM, led Murr et al. [35] to affirm that such methodology could extend traditional materials science and engineering, as far as allowing planning application-specific microstructural architecture in as-built components. 


\section{RESULTS}

Just a few austenitic stainless steel grades are nowadays manufactured by L-PBF process: AISI 304, AISI 304L and AISI 316L are the most common ones, the latter being the only one of them commercialized by systems manufacturers.

In Table 1 tensile testing results are reported and compared to standard minimum requirements, showing that:

- room temperature properties result higher than the minimum requirements usually applied for the selected stainless steel grades processed with conventional technologies, apart from fracture elongation;

- fracture elongation is the most negatively affected parameter, for samples tested in the as built condition;

Table 1 Tensile strength of austenitic stainless steel grades obtained from L-PBF, compared to standard reference values $(\mathrm{BD}=$ Building Direction; $\mathrm{YS}=$ Yield Strength; UTS= Ultimate Tensile Strength; El.= Elongation; SD= Self-developed; NR= Non reported; RT= Room Temperature; HT= Heat Treated; $\mathrm{H}=$ Horizontal; $\mathrm{V}=$ Vertical).

\begin{tabular}{|c|c|c|c|c|c|c|c|}
\hline Grade & Equipment & $\begin{array}{l}\begin{array}{l}\text { Relative density } \\
{[\%]}\end{array} \\
\end{array}$ & Cond. & BD & $\begin{array}{l}\text { Test } \\
\text { cond. }\end{array}$ & $\begin{array}{l}\text { YS } \\
\lfloor\mathrm{MPa}\rfloor \\
\end{array}$ & $\begin{array}{l}\text { UTS } \\
\text { [MPa| } \\
\end{array}$ \\
\hline \multirow{3}{*}{304} & \multirow{3}{*}{ SD } & \multirow{3}{*}{ NR } & \multirow{3}{*}{ As built } & $\mathrm{H}$ & \multirow{3}{*}{ RT } & 530 & 700 \\
\hline & & & & $45^{\circ}$ & & 370 & 540 \\
\hline & & & & $\mathrm{v}$ & & 450 & 550 \\
\hline $304 \mathrm{~L}$ & $\begin{array}{l}\text { 3D Systems ProX- } \\
300\end{array}$ & 99,99 & As built & - & RT & 485 & 712 \\
\hline $316 \mathrm{~L}$ & $\begin{array}{ll}\text { SLM Solutions } \\
125 \mathrm{HL}\end{array}$ & $95,99-99,30$ & $\begin{array}{l}\mathrm{HT} \\
1040^{\circ} \mathrm{C} / 4 \mathrm{~h} \\
\end{array}$ & $\mathrm{v}$ & RT & 376 & 637 \\
\hline \multirow{3}{*}{$316 \mathrm{~L}$} & \multirow{3}{*}{$\begin{array}{c}\text { SLM } \\
\text { Solutions } 280 \mathrm{HL}\end{array}$} & \multirow{3}{*}{$>99$} & \multirow{3}{*}{ As built } & $\mathrm{H}$ & \multirow{3}{*}{ RT } & 528 & 639 \\
\hline & & & & $45^{\circ}$ & & 590 & 699 \\
\hline & & & & $\mathrm{V}$ & & 439 & 512 \\
\hline \multirow{2}{*}{$316 \mathrm{~L}$} & \multirow{2}{*}{$\begin{array}{l}\text { Sisma } \\
\text { MYSINT100 }\end{array}$} & \multirow{2}{*}{$99,3-100$} & \multirow{2}{*}{ As built } & $45^{\circ}$ & \multirow{2}{*}{ RT } & $505-515$ & 650 \\
\hline & & & & $\mathrm{V}$ & & $430-495$ & $550-575$ \\
\hline $316 \mathrm{~L}$ & Renishaw AM250 & $\mathrm{NR}$ & As built & $\mathrm{H}$ & RT & 554 & 685 \\
\hline \multirow{4}{*}{$316 \mathrm{~L}$} & \multirow{4}{*}{ NR } & \multirow{4}{*}{ NR } & \multirow{4}{*}{ As built } & - & RT & 456 & 703 \\
\hline & & & & - & $250^{\circ} \mathrm{C}$ & 376 & 461 \\
\hline & & & & . & $1100^{\circ} \mathrm{C}$ & - & 300 \\
\hline & & & & . & $1200^{\circ} \mathrm{C}$ & . & 150 \\
\hline & & & & & & & \\
\hline
\end{tabular}
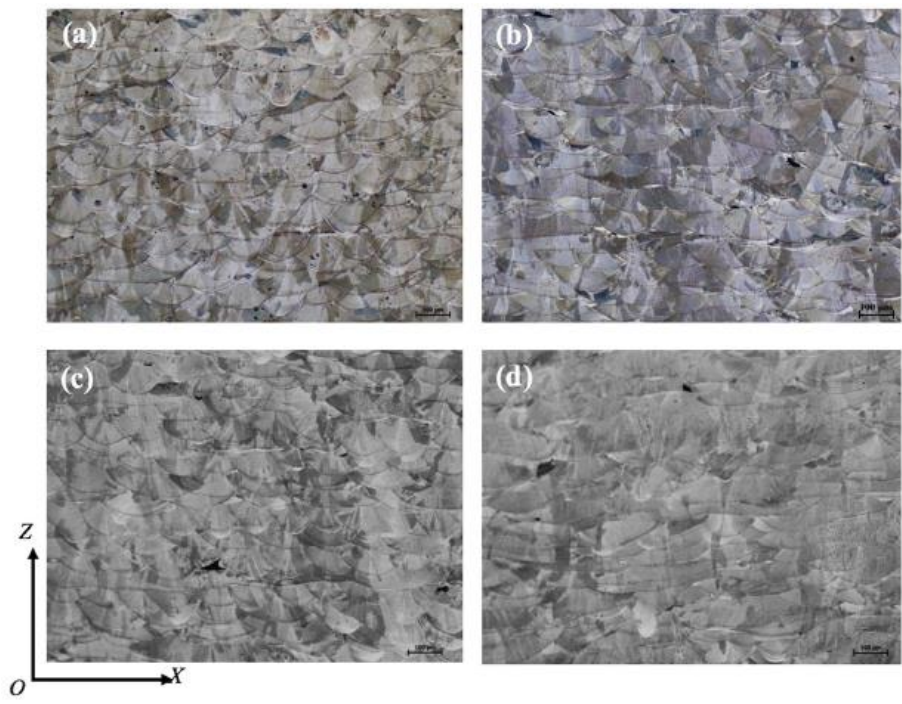

Figure 2 OM micrographs showing the microstructure of 316L samples fabricated at $200 \mathrm{~W}$ laser power, using different scanning strategies, (a) Meander; (b) Stripe; (c) Chessboard with $5 \times 5 \mathrm{~mm}$ islands; (d) Chessboard with $1 \times 1 \mathrm{~mm}$ islands. $\mathrm{Z}$ specifies the building direction.

Microstructural assessment of AISI304 and AISI316L grades showed that all samples are characterized by columnar grains (Figure 2, Figure 3 and Figure 4), independently of the alloy and of lased power scanning strategy (Figure 2 and Figure 3).

Some fatigue resistance results are reported in Table 2. Results show a beneficial machining operation effect, in particular in the case of high cycle fatigue (more sensitive to surface conditions or to the presence of cracks). On the contrary a negligible effect of surface roughness reduction is found in the case of low cycle fatigue tests. Microstructural characterization of both AIS 304 and AISI 316L grades allowed to state that:

- $\quad$ grain size does not depend on scanning strategy, once same laser power is kept constant (see Figure 2);

- $\quad$ grain size decreases with laser power decrease (Figure 3);

- $\quad$ as-built grains are show needle-like structures with medium size 500-800 $\mathrm{nm}$ and a high aspect ratio. These grains are oriented along different direction also if a single weld bead is considered (Figure 5).
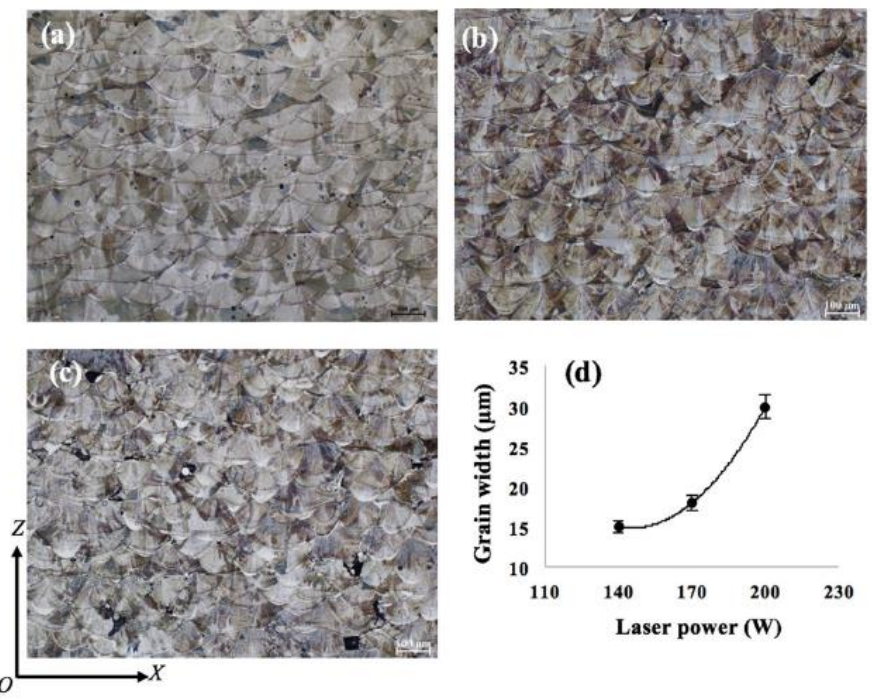

Figure $3 \mathrm{OM}$ micrographs of L-PBF 316L microstructure produced at different laser powers, (a) $200 \mathrm{~W}$; (b) $170 \mathrm{~W}$; (c) $140 \mathrm{~W}$; (d) grain width correlation to laser power values. $Z$ specifies the building direction.

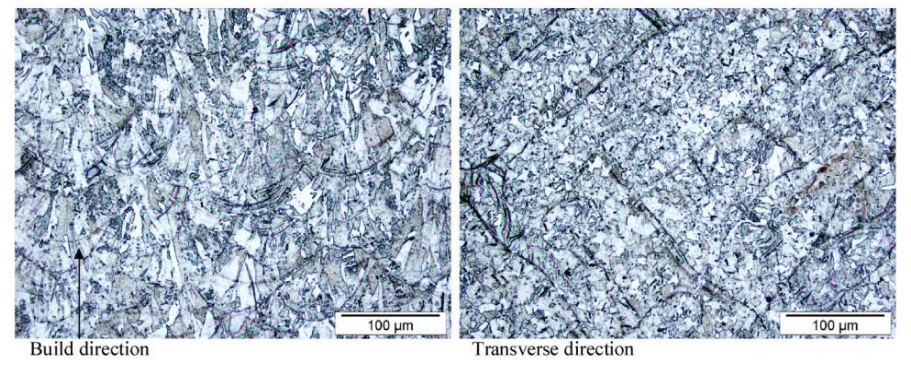

Figure 4 OM showing L-PBF 304 stainless steel microstructure, (a) along vertical cross section - heat flow effect is evident in the build direction and (b) nearly equiaxed grains in the planar direction, coincident to the layer top view. 

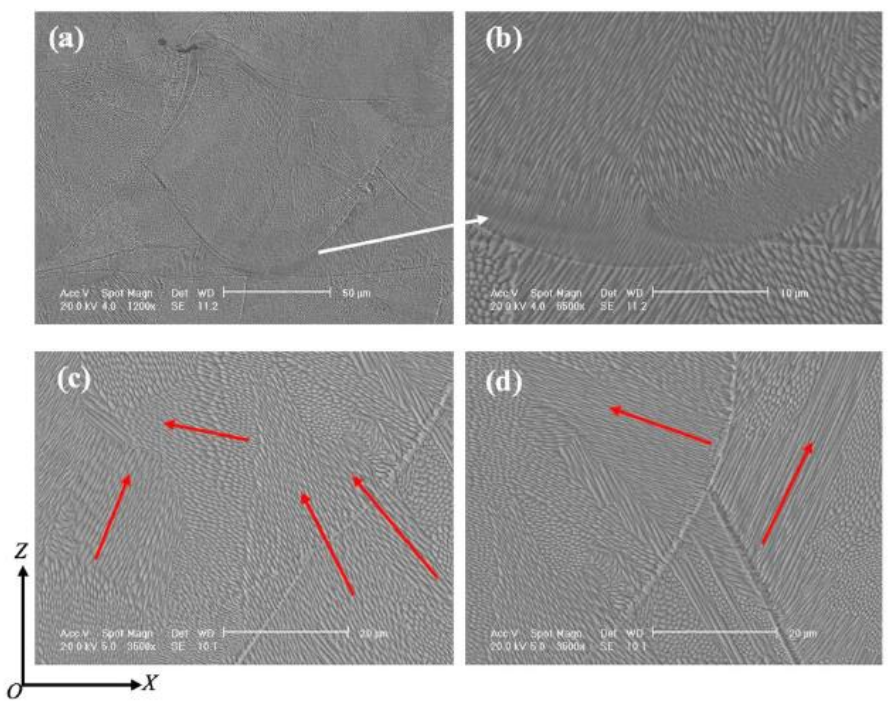

Figure 5 SEM micrographs showing the microstructure of 316L samples (laser power at 200W), (a) within a weld bead; (b) at the bottom region of (a); (c) grain structure beyond two layers; (d) grains in two adjacent weld beads. Red arrows point out grain growth direction. $\mathrm{Z}$ specifies the building direction.

Table 2 Fatigue endurance limits of L-PBF 316L samples, under different loading and surface conditions.

\begin{tabular}{|l|l|l|l|l|}
\hline Alloy & $\begin{array}{c}\text { Fatigue endurance at } \\
\mathbf{1 0}^{\mathbf{6}} \text { cycles }[\mathbf{M P a}]\end{array}$ & $\mathbf{R}$ & Surface condition & Ra $[\boldsymbol{\mu m}]$ \\
\hline 316L & 130 & -1 & As built & 13,29 \\
\hline 316L & 170 & -1 & Vibratory finished & 1,74 \\
\hline $316 \mathrm{~L}$ & 240 & -1 & Turned & 1,08 \\
\hline $316 \mathrm{~L}$ & 200 & 0,1 & As built & 10,0 \\
\hline $316 \mathrm{~L}$ & 256 & 0,1 & Machined & 0,4 \\
\hline $316 \mathrm{~L}$ & 269 & 0,1 & Polished & 0,1 \\
\hline $316 \mathrm{~L}$ & 108 & -1 & As built & NR \\
\hline $316 \mathrm{~L}$ & 267 & -1 & Turned & NR \\
\hline
\end{tabular}

\section{CONCLUSIONS}

The possibility to process austenitic stainless steel grades by L-PBF has been reported. The exploitation of L-PBF technique allows to obtain relevant benefits if the following issues are required:

- $\quad$ artefacts weight reduction;

- easy customization;

- complex internal features manufacturing.

The above listed advantages are quite important for stainless steel grades. In this frame, the adoption of L-PBF will manifest in a large material saving and efficiency improvement in many applications including biomedical devices and power production plant. L-PBF is particularly suggested for additive manufacturing stainless steels following its capability to manufacture complex features with a good compromise in terms of costs and times, without losing low oxides contamination.

The paper showed that austenitic stainless steel alloys are satisfactorily processed by L-PBF. Further, the obtained mechanical properties target stainless steels requirements for several applications. High mechanical properties are targeted since the porosity level achieved by L-PBF is quite low and comparable to conventionally processed materials.

The analysis of listed tested alloys, relative metallurgical microstructures and tensile strengths reveals that only a few stainless steel grades are actually processed by L-PFB. This item defines the path for further researches and exploitation.

\section{REFERENCES}

1. P. Marshall: Austenitic stainless steels: Microstructure and Mechanical Properties, Elsevier Applied Science Publisher, 1984.

2. L. Viet, J. Hye-Jin: Metals, 8, 2018, 815. DOI: $10.3390 /$ met 8100815 .

3. C. Xingrun, R. Xiang: Metals, 8, 2018, 1024. DOI: 10.3390/met8121024.

4. D. Hongjinng: Metals, 9, 2019, 74. DOI: 10.3390/met9010074.

5. A. Tachieva: Metals, $9,2019,347$. DOI: 10.3390/met9030347.

6. A. Prosviryakov: Metals, 9, 2019, 218. DOI: 10.3390/met9020218.

7. R. Rufini, O. Di Pietro, A. Di Schino: Metals, 8, 2018, 519. DOI: 10.3390/met8070519.

8. A. Di Schino, P.E. Di Nunzio: Acta Metallurgica Slovaca, 23, 2017, 62-71. DOI: 10.12776/ams.v23i1.852.

9. D. Manfredi, R. Bidulsky: Acta Metallurgica Slovaca, 23(3), 2017, 276-282. https://doi.org/10.12776/ams.v23i3.988.

10. P. Petrousek et al.: Acta Metallurgica Slovaca, 25(4), 2019, 283-290. https://doi.org/10.12776/ams.v25i4.1366.

11. M. Corradi, A. Di Schino, A. Borri, R. Rufini: Constr. Build. Mater., vol. 181, 2018, 335-346. DOI: 10.1016/j.conbuildmat.2018.06.034.

12. A. Borri, M. Corradi, G. Castori, A. Molinari: Constr. Build. Mater., 211, 2019, 594. DOI: 10.1016/j.conbuildmat.2019.03.197.

13. C. Gennari, M. Lago, B. Bögre, I. Mezaros, I. Calliari, L. Pezzato: Metals. 8 , 2018, 1074. DOI: 0.3390/met 8121074

14. A. Di Schino, M. Longobardo, G. Porcu. G. Turconi, L. Scoppio: NACE International Conference Series 2006, 062151-06125114.

15. G. Bregliozzi, A. Di Schino, J.M. Kenny, H. Haefke: Materials Letters, 57, 2003, 4505-4508. DOI: $10.1016 / \mathrm{S} 0167-577 \mathrm{X}(03) 00351-3$.

16. A. Di Schino, C. Guarnaschelli: Materials Science Forum, 638-642, 2019, 31883193. DOI: $10.4028 /$ www.scientific.net/MSF.638-642.3188.

17. A. Di Schino: Acta Metallurgica Slovaca, 22, 2016, 266-270. DOI: 10.12776/ams.v22i4.815

18. A. Di Schino, P. Di Nunzio. G.L. Turconi: Materials Science Forum, 558-559, 2007, 1435-1441. DOI: 10.4028/0-87849-443-x.1435.

19. L. Boulané-Petermann: Biofouling, 10(4), 1996, 275.

20. G. Bregliozzi, S.I.U. Ahmed, A. Di Schino, K.M. Kenny, H. Haefke: Tribol. Lett., 17, 2004, 697-704. DOI: 10.1007/s11249-004-8075-z.

21. A. Di Schino, L. Valentini, J.M. Kenny, Y. Gerbig, I. Ahmed, H. Haefke: Surf. Coat. Technol., 161, 2002, 224-231. DOI: 10.1016/S0257-8972(02)00557-1.

22. A. Di Schino, J.M. Kenny, G. Abbruzzese: J. Mater. Sci., 37, 2002, 5291-5298. DOI: $10.1023 / \mathrm{A}: 1021068806598$.

23. A. Di Schino, J.M. Kenny, I. Salvatori, G. Abbruzzese: J. Mater. Sci. , 36, 2001, 593-601. DOI: 10.1023/A:1004856001632.

24. L. Valentini, A. Di Schino, J.M. Kenny, Y. Gerbig, H. Haefke: Wear, 253, 2002, 458-464. DOI: 10.1016/S0043-1648(02)00140-0.

25. C Zitelli, P. Folgarait, A. Di Schino: Metals, 9, 2019, 731. DOI: 10.3390/met9070731.

26. Z. Brytan, M.A. Grande, M. Rosso, R. Bidulský, L.A. Dobrzański: Materials Science Forum, 672, 2011, 165.

DOI: 10.4028/www.scientific.net/MSF.672.165

27. T. Kvačkaj, L. Sokolová, M. Vlado, V. Vrchovinský: High Temperature Materials and Processes, 24, 2005, 139. DOI: 10.1515/HTMP.2005.24.2.139

28. R. Bidulsky, M. Actis Grande, E. Dudrova, M. Kabatova, J. Bidulska: Powder Metallurgy, 59(2), 2016, 121-127. DOI: 10.1179/1743290115Y.0000000022.

29. C. Wang, M. Wang, J. Shi, H. Dong, H: Scripta Materialia, 58, 2008, 492. DOI: 10.1016/j.scriptamat.2007.10.053.

30. T. DebRoy, H.L. Wei, J.S. Zuback, T. Mukherjee, J.W. Elmer, J.O. Milewski, A.M. Beese, A. Wilson-Heid, De, W. Zhang: Prog. Mater. Sci., 92, 2018, 112. DOI: 10.1016/j.pmatsci.2017.10.001

31. P. Krakhmalev, G. Fredriksson, K. Svensson, I. Yadroitsev, I. Yadroitsava, M. Thuvander, R. Peng: Metals, 8, 2018, 643. DOI: 10.3390/met8080643.

32. K. Ren, Y. Chew, J.Y.H. Fuh, Y.F. Zhang, G.J. Bi, Mater. Des., 162, 2019, 8093. DOI: 10.1016/j.matdes.2018.11.014.

33. T.M. Rodgers, J.D. Madison, V. Tikare: Comput. Mat. Sci., 135, 2017, 78-89. DOI: 10.1016/j.commatsci.2017.03.053.

34. K, Saeidi, F. Akhtar: Microstructure-Tailored Stainless Steels with High Mechanical Performance at Elevated Temperature. In Stainless Steels and Alloys; Duriagina, Z., Ed.; Intech Open, 2019, ISBN 978-1-78985-369-8.

35. L.E. Murr, S.M Gaytan, D.A. Ramirez, E. Martinez, J. Hernandez, K.N. Amato, P.W. Shindo, F.R. Medina, R.B. Wicker: J. Mater. Sci. Technol., 2012, 28. DOI: 10.1016/S1005-0302(12)60016-4. 